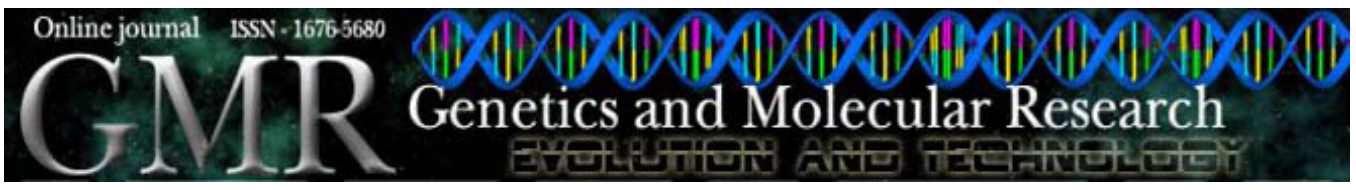

\title{
Phenotypic and RAPD diversity among 80 germplasm accessions of the medicinal plant isabgol (Plantago ovata, Plantaginaceae)
}

\author{
N. Singh, R.K. Lal and A.K. Shasany \\ Central Institute of Medicinal and Aromatic Plants \\ (Council of Scientific and Industrial Research), Lucknow, India \\ Corresponding author: R.K. Lal \\ E-mail: rk.lal@cimap.res.in
}

Genet. Mol. Res. 8 (3): 1273-1284 (2009)

Received May 13, 2009

Accepted August 5, 2009

Published October 27, 2009

\begin{abstract}
Plantago ovata, popularly known as isabgol, has great commercial and medicinal importance due to thin rosy white membranous seed husk. Isabgol seeds and husks have emollient, demulcent and laxative properties. We used both biometric and molecular techniques to assess the genetic variability and relatedness of 80 germplasm accessions of Plantago spp ( $P$. ovata, P. lanceolata, and $P$. major) collected both from India and abroad. The range of $\mathrm{D}^{2}$ values (2.01-4890.73) indicated a very high degree of divergence among the accessions. Based on the degree of divergence, 80 accessions/genotypes were grouped into seven clusters. Thirty-six accessions were analyzed through RAPD profiling for similarity and genetic distances, using 20 random primers. Intraspecific differences in all three species were smaller [range for $P$. ovata (217\%), P. lanceolata (3-15\%), P. major (2-11\%)] than interspecific
\end{abstract}


diversity. These highly divergent lines could be used to produce superior hybrids.

Key words: Plantago; Genetic diversity; Degree of divergence; RAPD markers

\section{INTRODUCTION}

The genus Plantago (family - Plantaginaceae) comprises 200 species, ten of which occur in India (Anonymous, 1969). Plantago ovata is one of these plants, valued for its seeds and husks, which have been used in indigenous medicine for many centuries all over the world. Seeds are believed to have cooling, demulcent effects and to be useful in inflammatory and biliary disorders of the digestive organs; they are also applied as a poultice for rheumatic and gouty swelling, and thought to be beneficial in the treatment of dysentery and irritation of the intestinal tract. The husk from the seed has the property of absorbing and retaining water, and hence, it works as an anti-diarrheal drug. The plant, of west Asian origin, was introduced into India during the Muslim settlement in the middle Ages.

India currently ranks first in the production and trade of Plantago ovata in the world market. Each year, India produces about 45,000 metric tons of isabgol seeds and 15,000 metric tons of seed husk from nearly 50,000 ha of cultivated land in India, where most production occurs in the States of Gujarat, Madhya Pradesh, Uttar Pradesh, Bihar, Haryana, and part of Rajasthan (especially in the Malwa tract and the northern belt). Some $90 \%$ of the seeds and husks are exported, making isabgol a major foreign exchange earner for India. Although Plantago psyllium (cultivated earlier in France), P. major, P. lanceolata, P. pumilla, P. coronopus, P. argentia, and P. lagopus are also grown in small quantities for mucilage, these species are only of small importance in the pharmaceutical industries.

In this study, genetic variability and the random amplified polymorphic DNA (RAPD) technique were used for the assessment of diversity for various traits in available germplasm collections assembled from different places in India and from abroad, as a prelude to crop improvement.

\section{MATERIAL AND METHODS}

\section{Plant materials}

The materials for the present investigation comprised eighty indigenous and exotic accessions/collections of diverse origin. Sixty-nine was from India, including sixty-one from Uttar Pradesh, five from Gujarat and one each from Uttaranchal, Himanchal Pradesh and Maharastra. Eleven were exotic, including three from Malaysia, two from the USA and one each from Pakistan, France, Hungary, Poland, Baluchistan and Bulgaria, of Plantago belonging to three species, namely Plantago ovata, P. lanceolata, and P. major (Table 1).

Thirty-six accessions were selected on both a geographical and morphological basis (Figure 1) to study the genetic divergence using RAPD markers (Table 1). 


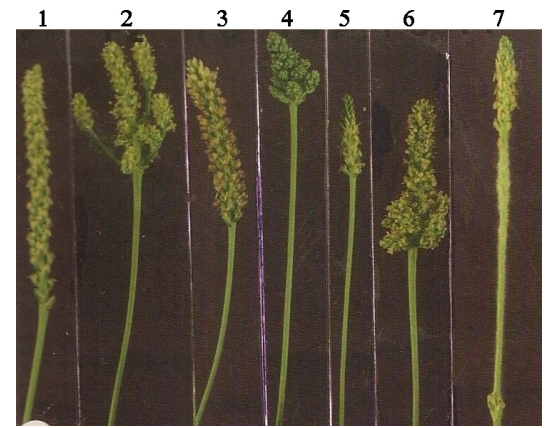

Figure 1. Morphological variations in panicles among the Plantago ovata accessions. $1=$ Normal; $2=$ Branched; $3=$ Feathery; $4=$ Club shaped; $5=$ Normal (check); $6=$ Club; $7=$ Cottony long.

Table 1. Geographical distribution and type of panicle of eighty accessions of Plantago.

\begin{tabular}{|c|c|c|c|c|c|c|c|}
\hline S. No. & $\begin{array}{l}\text { Accession } \\
\text { No. }\end{array}$ & $\begin{array}{l}\text { Type of } \\
\text { panicle }\end{array}$ & $\begin{array}{l}\text { Origin/Places } \\
\text { of collection }\end{array}$ & S. No. & $\begin{array}{l}\text { Accession } \\
\text { No. }\end{array}$ & $\begin{array}{l}\text { Type of } \\
\text { panicle }\end{array}$ & $\begin{array}{l}\text { Origin/Place } \\
\text { of collection }\end{array}$ \\
\hline 1 & PO $1 *$ & Normal & Bulgaria & 41 & PM $41^{*}$ & Normal & Uttar Pradesh (Lucknow), India \\
\hline 2 & PO $2 *$ & Normal & USA & 42 & PL 42 & Normal & Uttar Pradesh (Lucknow), India \\
\hline 3 & PO $3 *$ & Normal & USA & 43 & PM 43 & Normal & Uttar Pradesh (Lucknow), India \\
\hline 4 & PO $4 *$ & Normal & Pakistan & 44 & PL 44 & Normal & Uttar Pradesh (Lucknow), India \\
\hline 5 & PO $5^{*}$ & Normal & Maharastra, India & 45 & PL $45^{*}$ & Normal & Uttar Pradesh (Lucknow), India \\
\hline 6 & PO $6^{*}$ & Normal & Baluchistan & 46 & PL 46 & Normal & Uttar Pradesh (Lucknow), India \\
\hline 7 & PO $7 *$ & Normal & Uttaranchal (Pantnagar), India & 47 & PL 47 & Normal & Uttar Pradesh (Lucknow), India \\
\hline 8 & PO $8^{*}$ & Normal & Himanchal Pradesh, India & 48 & PM $48 *$ & Normal & Uttar Pradesh (Lucknow), India \\
\hline 9 & PO 9 & Normal & Gujarat, India & 49 & PL 49 & Normal & Uttar Pradesh (Lucknow), India \\
\hline 10 & PO 10 & Normal & Uttar Pradesh (Lucknow), India & 50 & PL 50 & Normal & Uttar Pradesh (Lucknow), India \\
\hline 11 & PO 11 & Normal & Gujarat (Sidhpur), India & 51 & PL 51 & Normal & Malaysia \\
\hline 12 & PO 12 & Normal & Uttar Pradesh (Lucknow), India & 52 & PL 52* & Normal & Malaysia \\
\hline 13 & PO $13^{*}$ & Normal & Uttar Pradesh (Lucknow), India & 53 & PL 53* & Normal & Malaysia \\
\hline 14 & PO 14 & Normal & Uttar Pradesh (Lucknow), India & 54 & PL 54 & Normal & Uttar Pradesh (Lucknow), India \\
\hline 15 & PO $15^{*}$ & Normal & Uttar Pradesh (Lucknow), India & 55 & PO 55 & Club & Uttar Pradesh (Lucknow), India \\
\hline 16 & PO $16^{*}$ & Normal & Uttar Pradesh (Lucknow), India & 56 & PO $56^{*}$ & Club & Uttar Pradesh (Lucknow), India \\
\hline 17 & PO 17 & Normal & Uttar Pradesh (Lucknow), India & 57 & PO 57 & Club & Uttar Pradesh (Lucknow), India \\
\hline 18 & PO 18 & Normal & Uttar Pradesh (Lucknow), India & 58 & PO 58 & Club & Uttar Pradesh (Lucknow), India \\
\hline 19 & PO $19 *$ & Normal & Gujarat (Mehsana), India & 59 & PO 59 & Club & Uttar Pradesh (Lucknow), India \\
\hline 20 & PO 20 & Normal & Uttar Pradesh (Lucknow), India & 60 & PO $60^{*}$ & Club & Uttar Pradesh (Lucknow), India \\
\hline 21 & PO 21 & Normal & Uttar Pradesh (Lucknow), India & 61 & PO 61 & Club & Uttar Pradesh (Lucknow), India \\
\hline 22 & PO 22 & Normal & Uttar Pradesh (Lucknow), India & 62 & PO 62 & Feathery & Uttar Pradesh (Lucknow), India \\
\hline 23 & PO 23 & Normal & Uttar Pradesh (Lucknow), India & 63 & PO 63 & Feathery & Uttar Pradesh (Lucknow), India \\
\hline 24 & PO 24 & Normal & Uttar Pradesh (Lucknow), India & 64 & PO $64^{*}$ & Club & Uttar Pradesh (Lucknow), India \\
\hline 25 & PO $25^{*}$ & Normal & Uttar Pradesh (Lucknow), India & 65 & PO 65 & Club & Uttar Pradesh (Lucknow), India \\
\hline 26 & PO $26^{*}$ & Normal & Gujarat, India & 66 & PO $66^{*}$ & Feathery & Uttar Pradesh (Lucknow), India \\
\hline 27 & PO 27 & Normal & Uttar Pradesh (Lucknow), India & 67 & PO $67^{*}$ & Feathery & Uttar Pradesh (Lucknow), India \\
\hline 28 & PO 28 & Normal & Uttar Pradesh (Lucknow), India & 68 & PO 68 & Club & Uttar Pradesh (Lucknow), India \\
\hline 29 & PO $29 * \mathrm{C}$ & Cottony long & Uttar Pradesh (Lucknow), India & 69 & PO $69^{*}$ & Club & Uttar Pradesh (Lucknow), India \\
\hline 30 & PL $30^{*}$ & Normal & Poland & 70 & PO 70 & Club & Uttar Pradesh (Lucknow), India \\
\hline 31 & PM $31 *$ & Normal & France & 71 & PO 71 & Club & Uttar Pradesh (Lucknow), India \\
\hline 32 & PO $32 *$ & Normal & Uttar Pradesh (Lucknow), India & 72 & PO $72 *$ & Branched & Uttar Pradesh (Lucknow), India \\
\hline 33 & PO $33^{*}$ & Normal & Uttar Pradesh (Lucknow), India & 73 & PO $73^{*}$ & Branched & Uttar Pradesh (Lucknow), India \\
\hline 34 & PO 34 & Normal & Uttar Pradesh (Lucknow), India & 74 & PO $74^{*}$ & Normal & Uttar Pradesh (Lucknow), India \\
\hline 35 & PO 35 & Normal & Gujarat, India & 75 & PO 75 & Feathery & Uttar Pradesh (Lucknow), India \\
\hline 36 & PO 36 & Normal & Uttar Pradesh (Lucknow), India & 76 & PO 76 & Club & Uttar Pradesh (Lucknow), India \\
\hline 37 & PO 37 & Normal & Uttar Pradesh (Lucknow), India & 77 & PO 77 & Branched & Uttar Pradesh (Lucknow), India \\
\hline 38 & PO 38 & Normal & Uttar Pradesh (Lucknow), India & 78 & PO78(check)* & Normal & Uttar Pradesh (Lucknow), India \\
\hline 39 & PL $39^{*}$ & Normal & Hungary & 79 & PO 79 & Normal & Uttar Pradesh (Lucknow), India \\
\hline 40 & PL $40^{*}$ & Normal & Uttar Pradesh (Lucknow), India & 80 & PO 80 & Normal & Uttar Pradesh (Lucknow), India \\
\hline
\end{tabular}

$\mathrm{PO}=$ Plantago ovata $; \mathrm{PM}=$ Plantago major $; \mathrm{PL}=$ Plantago lanceolata . Note: Accessions indicated with asterisks were selected to study genetic divergence using RAPD markers. 


\section{Methods}

The performance of eighty accessions/genotypes was recorded in a randomized block design replicated twice in two environments. Plot size for each treatment was one row $3 \mathrm{~m}$ in length with $10 \times 30 \mathrm{~cm}$ plant to plant and row to row spacing. The crop was fertilized with 60

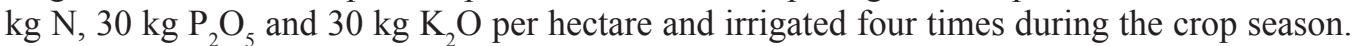
The plants were harvested in the month of April. Data were recorded on five randomly selected competitive plants in each line for the ten morphometric traits, plant height $(\mathrm{cm})$, branches per plant, panicles/plant, peduncle length $(\mathrm{cm})$, panicle length $(\mathrm{cm})$, days to maturity, seed yield (g/plant), husk yield (g/plant) and swelling factor.

Swelling factor $=$ volume of soaked-water $(\mathrm{mL})$ uptake $/$ amount of seeds $(\mathrm{g})$.

Mean data were subjected to statistical analysis for genetic divergence $\left(\mathrm{D}^{2}\right)$ and canonical analysis according to Mahalanobis (1936) and Rao (1952) among the different accessions/collections using a computer program package developed at the Data Processing Division of the CIMAP, Lucknow, based on the research of Singh and Choudhury (1979).

\section{DNA extraction and polymerase chain reaction amplification}

DNA was isolated from leaf tissue of samples according to the protocol described by Khanuja et al. (1999) and amplified by polymerase chain reactions. The reactions were carried out in a $25-\mu \mathrm{L}$ volume. The reaction tube contained $25 \mathrm{ng}$ DNA, 0.6 units Taq DNA polymerase, $0.25 \mu \mathrm{L}$ of each dNTPs $(10 \mathrm{mM}), 1.5 \mathrm{mM} \mathrm{MgCl}_{2}$ and $5 \mathrm{pmoL}$ decanucleotide primers. The amplifications were carried out using the DNA Engine Thermal Cycler (MJ Research, USA). The amplified products were loaded on a $1.2 \%$ agarose gel containing $0.5 \mu \mathrm{g} / \mathrm{mL}$ ethidium bromide and photographed using a Polaroid system. Custom-made decanucleotide primers (MAP01 to MAP20) were used for the analysis. The sequences of the primers MAP01 to MAP20 were AAATCGGAGC, GTCCTACTCG, GTCCTTAGCG, TGCGCGATCG, AACGTACGCG, GCACGCCGGA, CACCCTGCGC, CTATCGCCGC, CGGGATCCGC, GCGAATTCCG, CCCTGCAGGC, CCAAGCTTGC, GTGCAATGAG, AGGATACGTG, AAGATAGCGG, GGATCTGAAC, TTGTCTCAGG, CATCCCGAAC, GGACTCCACG, AGCCTGACGC, respectively.

\section{Data analysis}

Well-marked amplified fragments/bands were counted for the analysis. The similarity matrix obtained after multivariant analysis using Nei and Li's coefficient (1979) and the observed similarity coefficients were used to generate a tree for cluster analysis, using the UPGMA method (unweighted pair group method with arithmetic average).

\section{RESULTS}

The range of $\mathrm{D}^{2}$ values (2.01-4890.73) indicated a very high degree of divergence among the accessions. Based on the degree of divergence, 80 accessions/genotypes were grouped into 7 clusters (Figure 2), such that the genotypes within the clusters had smaller $\mathrm{D}^{2}$ values between themselves than those between clusters. Thus, intra-cluster distance for each 
of the clusters was observed to be less than the inter-cluster distances in all the cases. Cluster I, i.e., the biggest cluster, included 57 genotypes followed by cluster II (13), cluster III (5) and cluster IV (2). Each of the remaining 3 clusters comprised solitary individuals (Table 2).

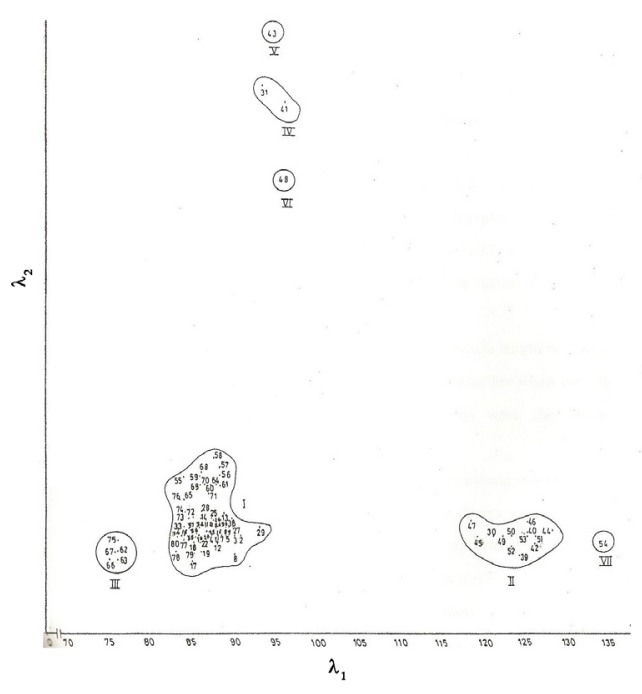

Figure 2. Spatial distribution of 80 accessions of Plantago.

\begin{tabular}{|c|c|c|}
\hline Clusters & Number & Accessions included in clusters \\
\hline I & 57 & 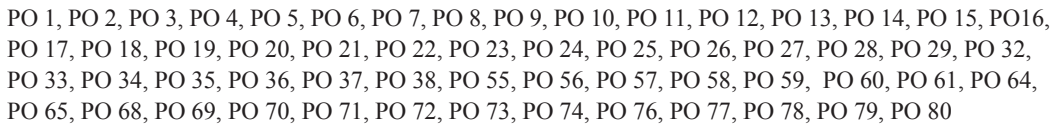 \\
\hline II & 13 & PL 30, PL 39, PL 40, PL 42, PL 44, PL 45, PL 46, PL 47, PL 49, PL 50, PL 51, PL 52, PL 53 \\
\hline III & 5 & PO 62, PO 63, PO 66, PO 67, PO 75 \\
\hline IV & 2 & PM 31, PM 41 \\
\hline $\mathrm{V}$ & 1 & PM 43 \\
\hline VI & 1 & PM 48 \\
\hline VII & 1 & PL 54 \\
\hline
\end{tabular}

The highest intra-cluster divergence (78.43 for cluster I) was invariably smaller than the lowest inter-cluster divergence between cluster IV and cluster V (122.66), thus authenticating the clustering patterns formed in this study. Intra-cluster divergence ranged from 12.93 (cluster III) to 78.43 (cluster I), whereas inter-cluster divergence ranged from 122.66 to 5372.48 between clusters IV and V and between clusters V and VII, respectively. The average inter-cluster divergence $\left(\mathrm{D}^{2}\right)$ was highest for cluster VII (3176.86) followed by cluster V (3152.12). It was lowest for cluster VI (1969.85). Other clusters were moderately divergent from other clusters, on average, 2039.55 to 2753.15 (Table 3). 


\begin{tabular}{|c|c|c|c|c|c|c|c|c|}
\hline Clusters & I & II & III & IV & V & VI & VII & $\mathrm{Av}\left(\mathrm{D}^{2}\right)$ \\
\hline I & 78.43 & 1431.63 & 245.32 & 2714.95 & 3655.89 & 1887.49 & 2302.00 & 2039.55 \\
\hline II & & 56.81 & 2350.25 & 3634.48 & 4636.04 & 2673.46 & 171.83 & 2482.95 \\
\hline III & & & 12.93 & 3433.39 & 4375.14 & 2739.28 & 3375.52 & 2753.15 \\
\hline IV & & & & 39.42 & 122.66 & 314.25 & 4385.30 & 2434.17 \\
\hline $\mathrm{V}$ & & & & & 0.0 & 750.61 & 5372.48 & 3152.12 \\
\hline VI & & & & & & 0.0 & 3454.02 & 1969.85 \\
\hline VII & & & & & & & 0.0 & 3176.86 \\
\hline
\end{tabular}

$\operatorname{Av}\left(D^{2}\right)=$ average $D^{2}$ values.

\section{Canonical analysis of genetic differentiation}

The divergence among eighty accessions of Plantago (P. ovata, P. lanceolata, and $P$. major) was measured and confirmed in terms of spatial distribution also by canonical analysis. Since the proportionate contribution by the first two canonical roots $\lambda_{1}(57.95 \%)$ and $\lambda_{2}(34.36 \%)$ was more than $90 \%$, the two-dimensional representation $\left(\lambda_{1}-\lambda_{2}\right.$ chart) was found adequate. The distribution of each individual against $\lambda_{1}$ and $\lambda_{2}$ coordinating axes is presented in Figure 2.

A very high divergence among the three species of Plantago was clearly shown by the spatial distribution. Accessions PO 62, PO 63, PO 66, PO 67, and PO 75 of P. ovata formed a separate cluster III and were also morphologically very different from the accessions of cluster I of P. ovata; however, accessions PO 55, PO 56, PO 57, PO 58, PO 59, PO 60, PO 61, PO 64, PO 65, PO 68, PO 69, PO 70, PO 71, and PO 76 were closer than the other members of cluster I and formed a separate group within the cluster, thus differentiated from the other accessions. Accession PO 29 was also farthest from all the other members of cluster I and occupied a separate space. Accessions of $P$. lanceolata were divided into two clusters, i.e., cluster II and cluster VII. Accessions PL 47 and PL 45 were farther from the other members of cluster II, whereas cluster VII had only one accession PL 54. Three clusters were formed by four accessions of $P$. major in which PM 43 and PM 48 were highly divergent and formed solitary clusters, whereas accessions PM 31 and PM 41 were included in a single cluster.

\section{Role of traits at different levels of differentiation}

At the inter-cluster level, panicles/plant (115.25\%), peduncle length $(99.76 \%)$, and panicle length $(77.16 \%)$ were the highest contributing characters when days to flower and maturity ( 8.42 and $8.64 \%$, respectively) were the lowest contributing characters (Table 4). The importance of different traits causing divergence at the primary and secondary axes of differentiation in terms of coefficients associated with $Z_{1}$ and $Z_{2}$ vectors were days to maturity $(0.522)$, plant height $(0.49)$, peduncle length $(0.290)$, and panicle length $(0.177)$ at the primary axis $\left(Z_{1}\right.$ vector) and panicles/plant $(0.683)$, days to maturity, (0.279), plant height $(0.231)$, and days to flowering $(0.196)$ at the secondary axis $\left(Z_{2}\right.$ vector). Above traits were the important contributors to the total divergence, respectively (Table 4). 


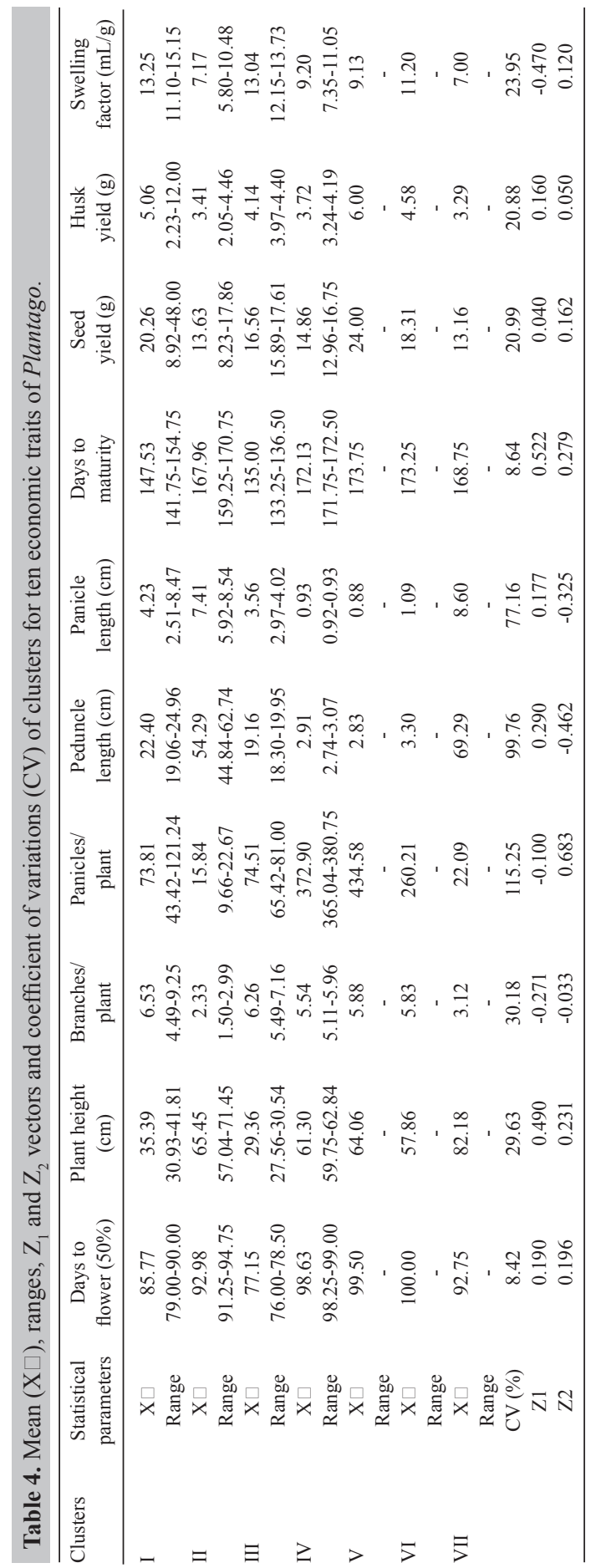




\section{Study the genetic divergence through RAPD markers}

In order to study the diversity at DNA level, twenty arbitrary primers were used for RAPD analysis. Fourteen primers responded by producing detectable bands (Figure 3). A total of 102 bands were scored against 36 genotypes across the three species of Plantago. Of 102 bands, $89(87.25 \%)$ were found to be polymorphic, while $5(4.9 \%)$ were monomorphic and 8 $(7.8 \%)$ were unique. When the scorable bands were examined in different species of Plantago, the $P$. ovate species showed a total of 57 bands among 27 genotypes/accessions. Of these 57 bands, $32(56.14 \%)$ were polymorphic, $23(40.35 \%)$ were monomorphic and $2(3.8 \%)$ were unique. In P. lanceolata, there were a total of 50 bands distributed within 6 accessions, of which $9(18 \%)$ were polymorphic, $35(70 \%)$ were monomorphic and $6(12 \%)$ were unique. Among the 3 accessions of $P$. major, a total of 46 bands could be detected, of which $4(8.7 \%)$ were polymorphic, 33 (71.74\%) were monomorphic and 5 (10.86\%) were unique.

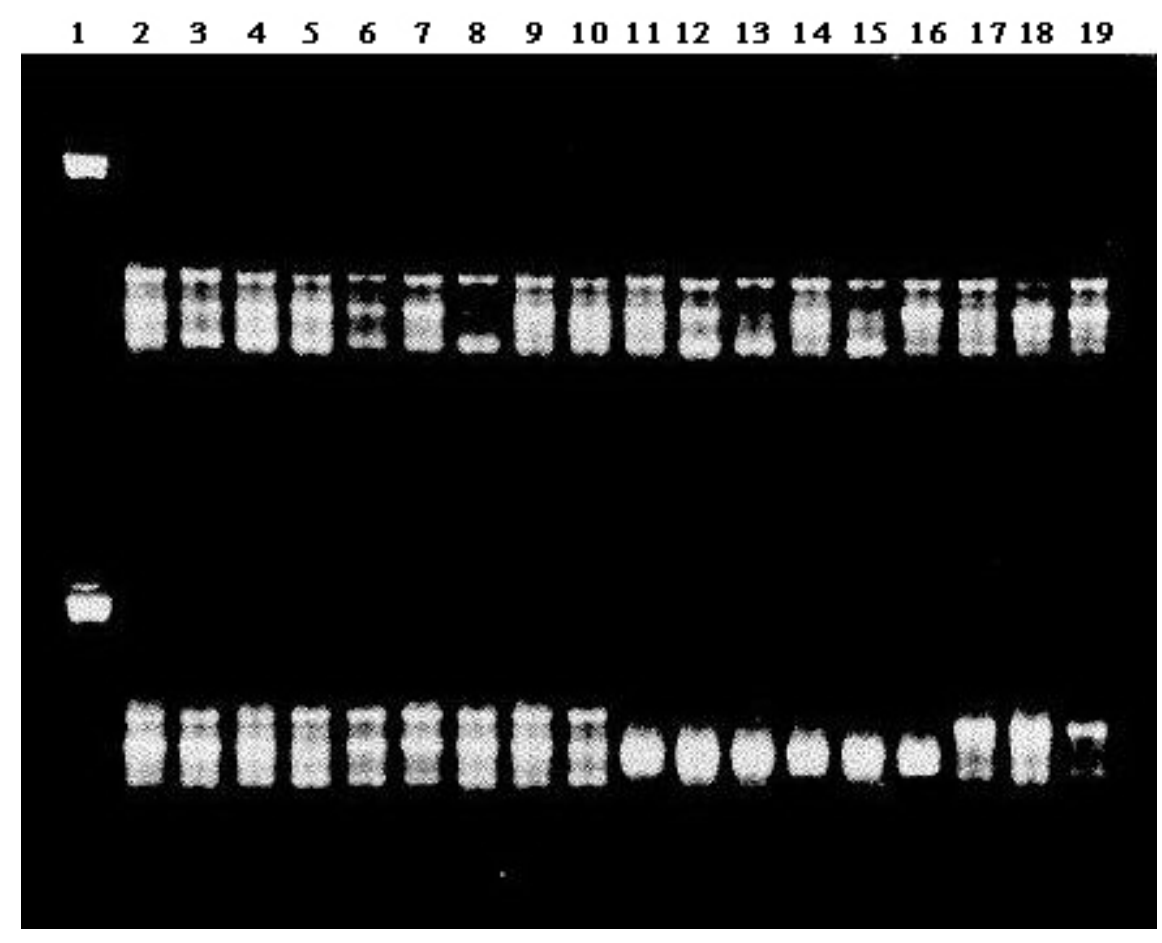

Figure 3. RAPD amplification of 36 accessions of Plantago with primer MAP06. 1st Row: Lane 1 = Molecular marker $\lambda$ DNA digested with HindIII; Lane 2 to Lane $9=$ PO 1 to PO 8; Lane $10=$ PO 13; Lane $11=$ PO 15; Lane $12=$ PO 16; Lane $13=$ PO 19; Lane $14=$ PO 25; Lane $15=$ PO 26; Lane 16 = PO 29; Lane $17=$ PO 32; Lane 18 = PO 33; Lane $19=$ PO 56. 2nd Row: Lane $1=$ Molecular marker; Lane $2=$ PO 60; Lane $3=$ PO 64; Lane $4=$ PO 66; Lane $5=$ PO 67; Lane $6=\mathrm{PO} 69 ;$ Lane $7=\mathrm{PO} 72 ;$ Lane $8=\mathrm{PO} 73 ;$ Lane $9=\mathrm{PO} 74 ;$ Lane $10=\mathrm{PO} 78 ;$ Lane 11 = PL 30; Lane $12=$ PL 39; Lane $13=$ PL 40; Lane $14=$ PL 45; Lane $15=$ PL 52; Lane $16=$ PL 53; Lane $17=$ PM 31; Lane $18=\mathrm{PM} 41 ;$ Lane $19=\mathrm{PM} 48 . \mathrm{PO}=$ Plantago ovata $; \mathrm{PL}=$ Plantago lanceolata $; \mathrm{PM}=$ Plantago major. 


\section{Cluster analysis based on RAPD}

To analyze the genetic distances within different accessions/genotypes of a species and among all the three species of Plantago, the similarity coefficients (Nei and Li, 1979) were used to generate a tree for cluster analysis using the UPGMA method. The resulting dendrogram (Figure 4) showed a differentiation into three major clusters, representing the three species of Plantago, namely P. ovata, P. lanceolata, and P. major. The three major clusters were observed in the phenogram. The first major cluster was represented by $P$. ovata. The diversity among the accessions of $P$. ovata was in the range of 2 to $17 \%$. Again, within the cluster of $P$. ovata, accessions PO 60 out-grouped completely and were the most diverse accessions among all of them. The next sub-cluster was constituted by the accessions PO 2, PO 6 and PO 19, which were acquired from the USA, Baluchistan and India (Gujarat), respectively. The other large sub-cluster included all other accessions with varying degree of similarity among them. The accessions PO 1 and PO 8 were observed sharing the highest level of similarity among themselves, but they belong to Bulgaria and India (Himanchal Pradesh), respectively. They clustered with PO 25 and PO 5, which were from India (U.P. and Maharashtra, respectively). In the next subculture, PO 4 belongs to Pakistan yet it clustered with PO 29, PO 26, and PO 67, which are Indian (U.P.) accessions. Accessions PO 4 and PO 29 were the most similar in this sub-cluster, whereas PO 26 and PO 67 were separated from these two and also between themselves. Another sub-cluster of accessions PO 72 and PO 73, which were from U.P. (Lucknow), clustered together, while PO 7 and PO15, belonging to different states, namely Uttaranchal (Pantnagar) and U.P. (Lucknow), respectively, also clustered together. The other sub-cluster included PO 3, PO 4, PO 78, and PO 16, in which PO 3 was obtained from the USA and other accessions from India (U.P.). The accession PO 13 was separated from all other accessions belonging to U.P. (Lucknow). The next large sub-cluster included PO 32, PO 33, PO 64, PO 56, and PO 69, in which PO 32 out-grouped from the rest. PO 33 and PO 66, PO 56 and PO 69 shared the highest level of similarity, whereas all the accessions in this sub-cluster belonged to U.P. (Lucknow).

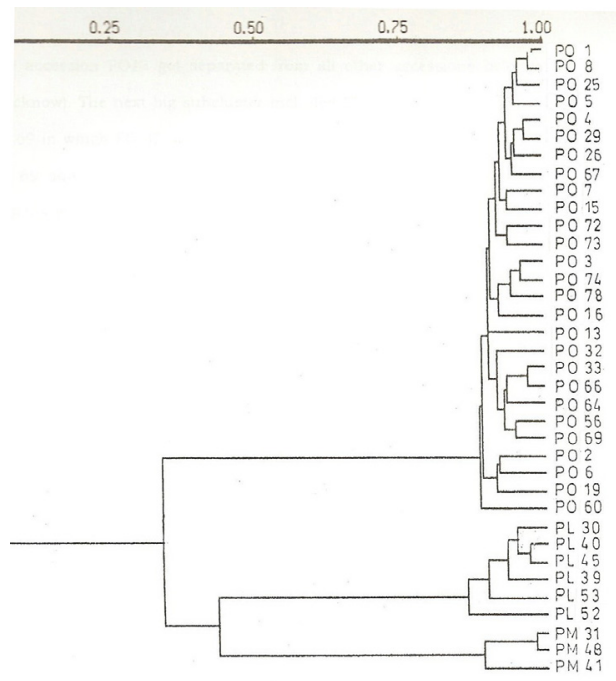

Figure 4. Similarity among Plantago accessions. 
Diversity was higher within the accessions of $P$. lanceolata compared to the accessions of $P$. ovata. The major subgroup with maximum similarity was observed between PL 40 and PL 45, which represents India. The French accession PL 30 out-grouped from the cluster, followed by PL 39 (Hungary), PL 52 and PL 53 (Malaysia).

Of the three accessions of $P$. major, PM 31 and PM 48 were the most similar, sharing maximum similarity in the genome, yet they were collected from Poland and India, whereas PM 41 (India, U.P.) formed a distinct subgroup, which is a diverse accession.

\section{Species-specific markers}

Species-specific markers among the three species of Plantago used in this experiment were found to differentiate $P$. ovata from $P$. lanceolata and $P$. major, and in another way: $P$. lanceolata from $P$. ovata and $P$. major from P. lanceolata and $P$. ovata, with the primers MAP02, MAP04, MAP05, MAP06, MAP09, MAP10, MAP12, and MAP19. The unique fragment sizes generated in Plantago for species-specific markers are presented in Table 5.

\begin{tabular}{|c|c|c|c|c|c|c|}
\hline \multirow[t]{2}{*}{ Primers } & \multicolumn{3}{|c|}{ No. of bands } & \multicolumn{3}{|c|}{ Molecular weight (bp) } \\
\hline & P. ovata & P. lanceolata & P. major & P. ovata & P. lanceolata & P. major \\
\hline MAP02 & 2 & 0 & 2 & $1000,79.43$ & - & $630.95,316.23$ \\
\hline MAP04 & 2 & 0 & 0 & $1122.01,407.38$ & - & - \\
\hline MAP05 & 1 & 1 & 2 & 251.18 & 316.23 & $794.33,398.11$ \\
\hline \multirow[t]{2}{*}{ MAP06 } & 2 & 2 & 2 & $794.33,398.11$ & 562.34 & \\
\hline & & & & & 316.23 & $630.96,501.19$ \\
\hline MAP09 & 1 & 1 & 0 & 478.63 & 549.54 & - \\
\hline MAP10 & 1 & 1 & 1 & 316.23 & 301.99 & 239.88 \\
\hline MAP12 & 2 & 1 & 1 & $251.19,158.48$ & 1000 & 223.87 \\
\hline MAP19 & 2 & 2 & 1 & $1995.26,398.11$ & $1000,316.23$ & 562.34 \\
\hline
\end{tabular}

\section{DISCUSSION}

The average $\mathrm{D}^{2}$ ranged from 1969.85 to 3176.86 , which indicates remarkable genetic divergence among the genetic accessions of isabgol. High morphological variation was also noted among the isabgol accessions for plant types and shape and size of panicles. As such, a considerable degree of divergence was found for all the traits in terms of $\mathrm{D}^{2}$ values, ranging from 2.01-4890.73. The cluster to cluster composition revealed that cluster I contained the accessions of isabgol from Uttar Pradesh, Maharashtra, Uttranchal, Himanchal Pradesh, Gujarat among the states of India, as well as from different countries, namely Bulgaria, USA, Pakistan, and Baluchistan. Similarly, cluster II included accessions from Poland, Hungary, Malaysia and India (U.P.), cluster III from Uttar Pradesh, and cluster IV from France and India (U.P.) and clusters V, VI and VII all from U.P. (India). The three genotypes, namely PM 43 of cluster V, PM 48 of cluster VI and PL 54 of cluster VII, were unique with each forming distinct clusters. Notably, all $P$. ovata accessions occurred in only two clusters, I and III (though cluster I can still be bifurcated), as did P. lanceolata accessions in V and VII. However, P. major with only 4 accessions formed 3 clusters IV-VI. Thus, $P$. major seems to have very high variability fol- 
lowed by P. lanceolata and P. ovata. The mean inter-cluster $\mathrm{D}^{2}$ values indicated the highest divergence between cluster V and VII $\left(\mathrm{D}^{2}=5372.48\right)$.

At the inter-cluster level, panicles/plant was the highest contributor and ranked first towards the total divergence $(115.25 \%)$. Days to $50 \%$ flowering was the least contributor towards the total divergence $(8.42 \%$, ranked 10th) (Table 4). The clusters V, VI and VII each with solitary and diverse accessions were distinct for a number of economic characters. For instance, the accession in cluster $\mathrm{V}$ was characterized by the highest mean values for panicles/ plant (434.58) and days to maturity (173.75 days) followed by seed yield ( $24.00 \mathrm{~g})$ and husk yield $(6.00 \mathrm{~g})$ (Table 4). Analysis of cluster composition revealed that the largest grouping comprised accessions collected from U.P., Maharashtra, Uttaranchal, Himanchal Pradesh and Gujarat among the states of India and Bulgaria, USA, Pakistan and Baluchistan. The smallest clusters were IV, V and VII, having one accession each belonging to France and India.

Accessions from U.P. (India) appeared to be highly divergent where they were represented in all clusters. The distribution pattern of accessions of diverse origin in a single cluster indicates that genetic diversity observed within isabgol genetic stocks was not related to geographical origin. Noted differences in plant characters probably occurred over time due to the migration of alleles among genetic stocks, cross-pollination/or spontaneous mutations and/ or free movement of plant materials from location to location. Thus, isabgol genotypes to be used for crop improvement/hybridization should be selected on the basis of quantified degree of divergence as opposed to geographical origin. The genotypes of cluster III and cluster I in $P$. ovata, of cluster II and cluster VII in P. lanceolata and of cluster IV, cluster V and cluster VI in $P$. major were highly divergent and may be used in hybridization programmes.

\section{Genetic relationship among the accessions of Plantago analyzed with RAPD markers}

The RAPD technique is being used for the analysis of diversity and defining the 'core collection' through identification of duplicates within the large germplasm collections (Virk et al., 1995). This technique is widely used for the identification of cultivars, phylogenetic relationship and, rational designing of breeding programs (Powell et al., 1996). A high level of polymorphism was observed on the specific level, but within species a low level of polymorphism was obtained. The number of unique bands was higher in $P$. lanceolata and $P$. major, as compared to $P$. ovata. No single primer was found that distinguishes all the accessions of a species, whereas MAP01, MAP10 and MAP16 gave maximum divergence within the species. The dendrogram shows a clear-cut variation among the species, as three major clusters were formed. It was observed that $P$. major and $P$. lanceolata were more similar as compared to $P$. ovata, which was out-grouped in the phylogenetic tree. From the RAPD study, the accessions could be differentiated, but intra-specific differences in all three species were much less (range for P. ovata, 2-17\%; for P. lanceolata, 3-15\%, and for P. major, 2-11\%) in comparison to inter-specific diversity. The grouping of accessions did not correlate with their geographical distribution as well as morphological variation. Within P. ovata, the accession number PO 29 (cottony long), PO 67 and PO 66 (feathery) were morphologically very distinct, but it could not be clearly detected by RAPD. PO 4 with simple inflorescence clustered with PO 29 (cottony long), PO 26 (simple) and PO 67 (feathery), similarly PO 33 (simple) and PO 66 (feathery) were clustered together; however, PO 72 and PO 73 having a branched panicle grouped together (Figure 1). Of the four plants having a club-shaped panicle, three shared the same 
group having one feathery and one simple type of inflorescence. Besides that, the speciesspecific monomorphic bands of different sizes were identified for $P$. ovata, $P$. lanceolata and $P$. major, which were used as markers for differentiating these three species from each other. Similar results have also been reported in Capsicum by Thull et al. (2008). Thus, the molecular analyses carried out using 36 accessions of Plantago were very efficient in detecting diversity among populations and between different species. Genotypes, both geographically and morphologically distinct, were not found to be appreciably distant genetically, but the genetic similarities obtained from the analysis can be used for the selection of parents to generate mapping populations and selecting parents for breeding purposes.

\section{REFERENCES}

Anonymous (1969). The Wealth of India. Raw Materials, VIII. Ph-RC. Publications and Information Directorate. Council of Scientific and Industrial Research, New Delhi, 146-154.

Khanuja SPS, Shasany AK, Darokar MP and Kumar S (1999). Rapid isolation of DNA from dry and fresh samples of plants producing large amounts of secondary metabolites and essential oils. Plant Mol. Biol. Rep. 17: 74.

Mahalanobis PC (1936). On the generalised distance in statistics. Proc. Nat. Inst. Sci. 2: 49-55.

Nei M and Li WH (1979). Mathematical model for studying genetic variation in terms of restriction endonucleases. Proc. Natl. Acad. Sci. U. S. A. 76: 5269-5273.

Powell W, Morgante M, Andre C, Hanafey M, et al. (1996). The comparison of RFLP, RAPD, AFLP and SSR (microsatellite) markers for germplasm analysis. Mol. Breed. 2: 225-238.

Rao CR (1952). Advanced Statistical Methods in Biometric Research. John Wiley and Sons Inc., New York.

Singh RK and Chaudhary BD (1979). Biometrical Methods in Quantitative Genetic Analysis. Kalyani Publishers, New Delhi.

Thull ST, Lal RK, Shasany AK, Darokar MP, et al. (2009). Estimation of phenotypic divergence in a collection of Capsicum species for yield-related traits. Euphytica 168: 189-196.

Virk PS, Ford-Lloyd BV, Jackson MT and Newbury HJ (1995). Use of RAPD for the study of diversity within plant germplasm collections. Heredity 74 (Pt 2): 170-179. 